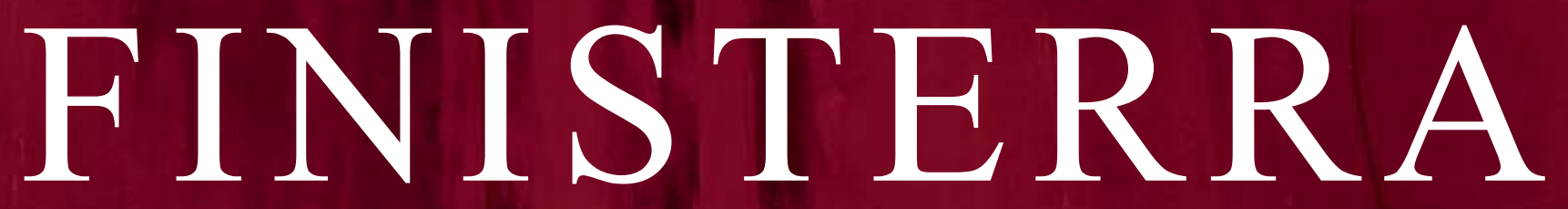

Revista Portuguesa de Geografia

Centro

de Estudos

Geográficos

Volume LII

Número 106

Dezembro 2017 


\title{
ILÍDIO DO AMARAL (1926-2017): UMA VASTA OBRA DEDICADA À GEOGRAFIA DAS REGIÕES TROPICAIS
}

Francisco Roque de Oliveira ${ }^{1}$

\author{
Aqui estou agora de coração em África \\ nesta noite fria e nu do capote das ilusões \\ ouvindo este sábio que tudo sabe tudo sabe de África \\ Francisco José Tenreiro (1963)
}

Ilídio do Amaral, professor catedrático jubilado da Faculdade de Letras da Universidade de Lisboa, faleceu em Lisboa no passado dia 24 de Março, com 90 anos de idade. Nascido em Luanda (Angola) a 3 de Setembro de 1926, Ilídio Melo Peres do Amaral foi autor de uma vasta obra dedicada à Geografia das regiões tropicais, tendo concluído ao longo de 60 anos de prolífera vida científica perto de 500 trabalhos, repartidos por domínios de especialidade muito diversos, com particular incidência para as temáticas da Geomorfologia, Geografia Urbana, Geografia Política, Geografia Histórica e História da Geografia. Angola e o arquipélago atlântico de Cabo Verde constituíram os espaços privilegiados dos seus estudos de Geografia Física e Humana. No panorama da Geografia portuguesa do século XX, Ilídio do Amaral terá sido também o geógrafo mais vezes chamado a desempenhar funções institucionais e públicas de relevo, sobressaindo os cargos de vice-presidente e presidente em exercício do Instituto de Alta Cultura (1971-1976), organismo sob tutela do Ministério da Educação responsável pela formulação da política científica e difusão internacional da língua e cultura portuguesas, e de vice-reitor e reitor da Universidade de Lisboa (1975-1979), coincidindo com o período particularmente difícil da transição para o regime democrático em Portugal (Ferreira, 2013, p. 370-371). Entre outros, desempenhou ainda os cargos de vice-presidente da Junta de Investigações Científicas do Ultramar (1979-1980) e de director do Centro de Geografia do Instituto de Investigação Científica Tropical (1984-2005), instituição que sucedeu à Junta depois do fim do império colonial português e de instaurada a democracia, reorientando os respectivos objectivos de acordo com a pragmática própria da cooperação científica internacional e da ajuda pública ao desenvolvimento prestada aos novos países de expressão portuguesa em África (IICT, 1983, p. 145-151; Castelo, 2012, p. 392-403; 2013, p. 359-387).

1 Professor Auxiliar e Investigador Efetivo do Centro de Estudos Geográficos do Instituto de Geografia e Ordenamento do Território da Universidade de Lisboa, R. Branca Edmée Marques, 1600-276, Lisboa, Portugal. E-mail: f.oliveira@campus.ul.pt 
Durante vários anos foi director adjunto do Centro de Estudos Geográficos da Universidade de Lisboa, que transformou «de oficina em fábrica», como disse em certa circunstância o seu então director, Orlando Ribeiro, referindo-se às múltiplas tarefas a que Ilídio do Amaral não se furtou neste Centro fundado em 1943 com o apoio do Instituto de Alta Cultura (Ribeiro, 2017 [1972], p. 783). Em 1967, coube-lhe organizar o I Seminário Internacional de Geografia, evento que confirmou a projecção internacional do Centro de Estudos Geográficos depois da visibilidade alcançada no imediato pós-guerra, quando Ribeiro assumira a organização do XVI Congresso Internacional da Geografia, em 1949 (Ribeiro, 1968). Fora da Faculdade de Letras de Lisboa, Amaral prestou colaboração docente ou institucional à generalidade das Universidades portuguesas e das antigas colónias portuguesas em África, e foi professor visitante em diversas universidades estrangeiras, sobretudo do Brasil. No biénio de 1965-1966, presidiu à direcção da Sociedade Portuguesa de Espeleologia, período que se reconhece ter correspondido a uma reorganização e promoção geral das actividades desta Sociedade (SPE, 2017). Entre 1984 e 1989, foi presidente da comissão instaladora da Universidade Internacional (Lisboa), tendo sido depois o seu primeiro reitor. Integrou ainda diversas outras instituições, como a Academia das Ciências de Lisboa, a Academia Portuguesa de História, a Academia Internacional de Cultura Portuguesa, a Sociedade de Geografia de Lisboa e a Royal African Society (Londres). Fez parte da direcção da revista Finisterra (1966-1979), editada pelo Centro de Estudos Geográficos da Universidade de Lisboa e que fundou em conjunto com Orlando Ribeiro e Suzanne Daveau, e encabeçou a comissão editorial da revista Garcia de Orta - Série de Geografia (1973-2002), sucessivamente publicada pela Junta de Investigações do Ultramar e pelo Instituto de Investigação Científica Tropical. Integrou também os corpos editoriais da Revista Internacional de Estudos Africanos (Lisboa) e Geografia (Rio Claro, Brasil).

Depois de realizar parte dos seus estudos secundários em Angola, Ilídio do Amaral fixou-se em Lisboa em 1943, onde viria a frequentar o curso de Contabilidade do Instituto Comercial de Lisboa, que o preparou para uma breve carreira na actividade bancária em Lisboa e Luanda. Inscrito como aluno voluntário na licenciatura em Geografia da Universidade de Lisboa, aí submeteu em 1956 uma dissertação intitulada São Paulo de Assunção de Luanda, que constituiu o primeiro exemplo de monografia sobre um tema das regiões tropicais apresentada em provas de licenciatura em Geografia nesta Universidade (Amaral, 1979, p. 13; Amaral \& Amaral, 1996, p. 7; 2016, p. 13; cf. Almeida et al., 2003, p. 354). Este trabalho inaugura também a primeira linha de pesquisas que consolidou, consagrada à geografia urbana da África subsariana e, em particular, ao caso de Luanda. Mais de uma década depois, esta série de trabalhos será coroada com a publicação do livro Luanda. Estudo de Geografia Urbana (Amaral, 1968), obra premiada pela Sociedade de Geografia de Lisboa e pela Câmara Municipal de Luanda, que explora a génese e evolução da cidade, as actividades urbanas e incorpora os contributos de autores como Georges Balandier, Jean Dresch, Guy Lasserre, Pierre Monbeig, Milton Santos e Jean Tricart, tal como os estudos conjuntos de Raymond Murphy, J. E. Vance Jr. e Bart Epstein sobre a estrutura interna do CBD. A cidade sul-africana de Joanesburgo (Amaral, 1966e) e Beira, em Moçambique (Amaral, 1969a), constituem outros casos de cidades africanas que Amaral investigou enquanto sistematizava a sua compreensão sobre o fenómeno da urbanização em contexto angolano em Ensaio de um estudo geográfico da rede urbana de Angola (Amaral, 1962).

Seguindo o protocolo da Universidade portuguesa da época, em 1958 Ilídio do Amaral ingressa como professor extraordinário na Faculdade de Letras da Universidade de Lisboa a convite de Orlando Ribeiro, que aí coordenava o ensino da Geografia. Começa por ter a seu cargo as cadeiras de Geografia Económica e Climatologia, a que depressa se acrescentaram a Geografia Urbana e a Geomorfologia e onde deu particular destaque aos territórios das regiões tropicais. Em paralelo, inicia também uma colaboração intensa com a Junta de Investigações Científicas do Ultramar no quadro de dois dos organismos científicos constituídos no âmbito da Junta, ambos sediados no Centro de Estudos Geográficos e dirigidos por Ribeiro: o Agrupamento Científico de Preparação de Geógrafos para o Ultramar Portu- 
guês, instituído em 1958 e onde Amaral trabalhou como bolseiro, e a Missão de Geografia Física e Humana do Ultramar, criada em 1960 e para a qual foi um dos cinco adjuntos nomeados (MU, 1968, p. 24 e 97). É sabido que a actividade destes organismos, funcionando sob a égide da Junta, reflecte, em última instância, o contexto internacional decorrente da conferência de Bandung, de 1955, e os ajustamentos da política científica associada às questões coloniais que Portugal empreendeu durante as últimas duas décadas do seu império (Castelo, 2012, p. 399-401; Cruz, 2016, p. 72-77; Oliveira, 2016, E47).

Foi nesse quadro que, logo em 1959, Ilídio do Amaral iniciou os trabalhos de campo tendentes à elaboração de uma dissertação de doutoramento em Geomorfologia regional, sobre o nordeste de Angola. Em 1960 - ano em que vê ser publicado na colecção «Estudos, Ensaios e Documentos» da Junta de Investigações do Ultramar Aspectos do povoamento branco de Angola, livro que inclui uma síntese histórica sobre a ocupação portuguesa da então colónia, a cartografia da distribuição geográfica da população e uma análise demográfica com base nos dados do censo de 1950 (Amaral, 1960) -, regressará a Angola para uma segunda missão de estudo enquadrada no seu projecto de doutoramento sobre a evolução do relevo entre os rios Loge e Cuanza, o Atlântico e a Baixa do Cassange (Amaral, 1969b, p. 8-9). No entanto, a sublevação camponesa iniciada nessa mesma região angolana em Março de 1961, considerada como o começo da Guerra Colonial que Portugal a breve trecho travaria em simultâneo nos teatros de Angola, Guiné e Moçambique e se prolongou até 1974, inviabilizou a realização deste projecto de pesquisa. Em resultado disso, Ilídio do Amaral decide submeter às provas de doutoramento um estudo focado na maior ilha do arquipélago de Cabo Verde. Trata-se da monografia Santiago de Cabo Verde. A Terra e os Homens (Amaral, 1964), prontamente publicada pela Junta de Investigações do Ultramar e premiada nesse mesmo ano pela Academia das Ciências de Lisboa. Sempre muito próximo dos geógrafos e da Geografia tropical produzida de Lisboa por esses anos, Pierre Gourou dedicar-lhe-ia uma longa recensão, publicada nas páginas dos Annales de Géographie em 1968 (Gourou, 1968).

Este estudo sobre a ilha de Santiago insere-se numa sequência de trabalhos sobre as ilhas do Atlântico gizada por Orlando Ribeiro de acordo com o modelo clássico da Geografia Regional e a inspiração confessa na abordagem integrada deste conjunto insular deixada em suspenso desde os trabalhos de Elisée Reclus (Ribeiro, 1954, p. 13-14). Tal linha de estudos veio a constituir um dos traços característicos da produção dos geógrafos de Lisboa, fortemente orientada para as regiões tropicais: às monografias do próprio Orlando Ribeiro sobre a ilha da Madeira (1949) e a ilha cabo-verdiana do Fogo (1954), seguiram-se aquelas de Raquel Soeiro de Brito sobre a ilha de São Miguel, nos Açores (1955), e de Francisco Tenreiro sobre São Tomé, no golfo da Guiné (1961) (Amaral, 1979, p. 14-15; Ferreira, Gaspar \& Medeiros, 1986, p. 66 e 74-75). Reeditada pela Associação das Universidades de Língua Portuguesa em 2007, Santiago de Cabo Verde sobressai por uma original e pertinente hierarquização das matérias abordadas, que se iniciam com um capítulo sobre «O clima e o tempo» que subverte a sequência dos temas da Geografia Física aplicada nas monografias que seguiam o esquema «clássico» assente por Albert Demangeon em La Picardie et les régions voisines (1905), assim como pela bibliografia actualizada, onde os especialistas ressaltam a leitura do estudo de Guy Lasserre sobre a Guadalupe e a sintonia com as mais modernas teorias explicativas da circulação atmosférica geral (Rebelo, 1992, p. 1565-1566; Medeiros, 1999, p. 5-6; Rebelo, 1999, p. 47-48; Almada, 2014, p. 121-122).

Na década que se seguiu à publicação desta monografia, Ilídio do Amaral continuou a dedicar a sua atenção ao aprofundamento de determinados aspectos geomorfológicos do litoral da ilha de Santiago (Amaral, 1967a; 1974a). O arquipélago cabo-verdiano voltaria a estar no cerne das suas preocupações científicas quando animou a publicação da Bibliografia geral de Cabo Verde (2 vols., 1980-1981) e a Bibliografia Geográfica de Cabo Verde (1. ${ }^{\circ}$ vol., 1995, em colaboração com Ezequiel Correia e António Gonçalves) (Amaral, 1980-1981a; Correia, Amaral \& Gonçalves, 1995). Em qualquer caso, a partir do final da década de 1960 Angola e a respectiva geomorfologia impor-se-ão definitivamente como o espaço e o tema da maior parte dos seus estudos em Geografia Física (Ferreira, Gaspar \& Medeiros, 
1986, p. 66; Amaral 1979). Esta linha central da sua pesquisa fora lançada ainda em 1961, com um trabalho sobre o relevo entre os rios Zaire e Loge elaborado em parceria com Orlando Ribeiro e Mariano Feio, autor que desde meados da década de 1940 publicava com regularidade sobre diversos aspectos da geomorfologia da Angola (Ribeiro, Feio \& Amaral, 1961; Amaral, 1979, p. 15-16). Ilídio do Amaral retomaria o tema das aplanações e do seu escalonamento em Aspectos do relevo do Noroeste de Angola entre os rios Loge e Cuanza (Amaral, 1970). Ao mesmo tempo, iniciava uma série de artigos mais autónoma com 'Inserberge' (ou montes-ilhas) e superfícies de aplanação na bacia do Cubal da Hanha, em Angola e Formas de 'Inselberge' (ou montes-ilhas) e de meteorização superficial e profunda em rochas graníticas do Deserto de Moçâmedes (Angola), na margem direita do rio Curoca (Amaral, 1969c; 1973a). Datam também desses anos diversos outros estudos sobre formas cársicas no nordeste e no sudoeste de Angola (Amaral, 1973b; 1973c) e sobre as paisagens morfológicas do deserto de Moçâmedes (Amaral, 1973d; 1974b; 1977; 1982a; 1985; cf. Amaral, 1979, p. 15-16; 1992, p. 1624-1625). Vale recordar que todas estas pesquisas foram alicerçadas em trabalho de campo regular empreendido a partir de $1964 \mathrm{em}$ Angola, que por regra decorreu em paralelo com a investigação que Ilídio do Amaral realizava sobre a geografia urbana de Angola, África do Sul e Moçambique, tendo também aproveitado excursões e viagens de estudo em França e Espanha. Entre Dezembro de 1965 e Julho de 1966, beneficiou ainda de uma bolsa da Fundação Calouste Gulbenkian para a realização de um estágio no Instituto de Geografia da Universidade de Munique focado no estudo dos problemas de evolução do relevo terrestre, onde foi orientado por Herbert Louis, oportunidade que Amaral voltou a utilizar para estudar aspectos da evolução urbana dessa e de outras cidades alemãs. Em 1969, já na qualidade de professor convidado, leccionaria na Universidade de Munique um Seminário de Geomorfologia Tropical (Amaral, 1969b, p. 6-12; Amaral \& Amaral, 1996, p. 10).

O trabalho de Ilídio do Amaral sobre o inselberg do Cubal da Hanha, de 1969, deu a medida do cientista que até à data mais profundamente fora capaz de se integrar em Portugal nas perspectivas climática e litológica da Geomorfologia (Rebelo, 1992, p. 1569-1571). Sobressai também a leitura crítica que paralelamente foi capaz de oferecer sobre alguma da bibliografia internacional de referência relativa à Geografia Física publicada por esses anos, conforme o exemplo dado nas páginas do $1 .^{\circ}$ número da Finisterra (1966). Entre outras, assinou aí recensões a The Morphology of the Earth (1962) de Lester C. King, Das Klima der Vorzeite (1961) de Martin Schwarzbach, Principes et méthodes de la Géomorphologie (1965) de Jean Tricart, Traité de Glaciologie (vol. 1, 1964) de Louis Lliboutry, Précis d'hydrologie marine et continentale (1965) de André Guilcher, Theoretical geomorphologie (1964) de Adrian E. Scheidegger, Weltkarten zur Klimakunde (1963) de Helmut Landsberg, Horst Lippmann, Karlheinz Paffen e Carl Troll e Klimadiagram-Weltatlas (1960 e 1964) de Helmut Walter e Heinrich Leith (Amaral, 1966a; 1966b; 1966d; 1966f). Obras entretanto tornadas clássicas como Allegemeine Klimageographie (1964) de Joachim Blüthgen, The History of the study of landforms or the development of Geomorphology de Richard J. Chorley, Anthony J. Dunn e Robert P. Beckinsale (vol. 1, 1964) e The Earth Sciences de Arthur N. Strahler (2. ${ }^{a}$ ed., 1965) serão recenseadas por si logo no ano seguinte (Amaral, 1967b). Não menos revelador da sua destreza e do seu método é o facto de Amaral ter conseguido intercalar no referido número inaugural da revista Finisterra recensões críticas a Megalopolis (1961) de Jean Gottmann e Land use in central Cape Town (1965) de David Hywel Davies (Amaral, 1966c; 1966g). Por outro lado, a persistência das suas preocupações por aspectos específicos da geomorfologia de Angola é patente em títulos muito mais recentes como Luanda e os seus dois arcos complexos de vulnerabilidade e risco (Amaral, 2002a) e O rio Cambongo-Negunza e os seus afluentes: um exemplo da complexidade de padrões de drenagem em Angola (Amaral, 2006), servindo como testemunho eloquente de uma excepcional longevidade científica.

Além da colaboração pontual emprestada à Encyclopaedia Britannica, Ilídio do Amaral contribuiu para a Enciclopédia Luso-Brasileira de Cultura com dezenas de entradas de temática geográfica, sintoma- 
ticamente iniciadas em 1963 com um extenso texto sobre a geografia física de África (Amaral, 1963) e concluídas mais de três décadas depois com uma reflexão de teor geopolítico intitulada $A$ África no limiar do século XXI: um continente em crise (Amaral, 1995). Contudo, na transição da década de 1970 para 1980 assinala-se nova evolução de interesses na sua obra. O primeiro indício desta metamorfose traduz-se por uma série de documentos sobre política e gestão científica e tecnológica, com frequentes incursões em matérias específicas das Ciências Sociais e Humanas em África, e que se manterá muito presente até ao final dos anos 90. Trata-se de um reflexo directo das sucessivas funções que foi chamado a desempenhar em organismos universitários e de investigação científica, assim como das actividades de consultor que realizou junto de instituições como a Fundação Calouste Gulbenkian e a UNESCO (Amaral \& Amaral, 1996, p. 11-12; 2016, p. 23-24 e 56-84). Em paralelo, desenvolveu um interesse crescente pela sistematização de actividades e de bibliografia pertinente relativa à «Escola geográfica de Lisboa», designação que fora atribuída aos geógrafos trabalhando em torno de Orlando Ribeiro por alguns dos seus pares franceses mais próximos, como Pierre Gourou (1958, p. 367, n. 2). Quer as nótulas periódicas que dedicou à Geografia praticada no Curso Superior de Letras e na Faculdade de Letras da Universidade de Lisboa desde o início do século XX (Amaral, 1981a; 1982b; 1983a; 1986b), quer as sínteses que propôs sobre a contribuição dos geógrafos portugueses organizados em torno do Centro de Estudos Geográficos da mesma Universidade para o conhecimento das regiões tropicais (Amaral, 1979; 1983b; 1992), quer ainda os diversos testemunhos que deixou sobre alguns dos seus contemporâneos (Amaral, 1963-1964; 1981b; 1981c; 1984; 1997a; 2010; Amaral \& Amaral, 1984a), constituem repositórios imprescindíveis para quem hoje pretenda realizar uma visão de conjunto sobre a Geografia portuguesa e o desenvolvimento da ciência em Portugal no século XX. Neste capítulo, merecem destaque as cerca de 3000 referências incluídas e comentadas na Bibliografia Geográfica de Portugal - Segundo volume 1947-1974 (1982), compilação orientada por Ilídio do Amaral em parceria com Suzanne Daveau (Amaral \& Daveau, 1982), e que actualizou a primeira versão deste importante projecto bibliográfico, concretizada em 1948 por Mariano Feio a partir da bibliografia preparada por Hermann Lautensach para o Geographisches Jahrbuch (vol. 45, 1931 e vol. 59, 1948) e acrescentada por este geógrafo alemão no final do 2. ${ }^{\circ}$ volume de Portugal. Auf Grund eigener Reisen und der Literatur (1937) (Lautensach \& Feio, 1948).

No longo percurso científico de Ilídio do Amaral, a Geografia Política e a Geografia Histórica veriam entretanto afirmar-se como dois outros campos de interesse privilegiado, tendo sempre África - e uma vez mais Angola - como principal objecto de estudo. Estas temáticas surgem com frequência articuladas num mesmo trabalho, para além de estabelecerem vínculos profundos com outros domínios do conhecimento, com destaque para a História, a Ciência Política e as Relações Internacionais. No início da década de 1980, num contexto marcado pelas incursões militares da República da África do Sul em território angolano, Amaral elabora um longo relatório focado na génese do troço de fronteira entre o rio Cumene e o rio Cubango. Este trabalho foi produzido no âmbito do grupo de estudos de Geografia das Regiões Tropicais que coordenava no Centro de Estudos Geográficos, tendo tido uma versão revista e definitiva publicada pouco depois nas páginas da Garcia de Orta (Amaral, 1980-1981b; 1982c). Seguir-se-á um conjunto de ensaios progressivamente alargado à generalidade das matérias relativas à partilha de Africa após a Conferência de Berlim de 1884-1885, à discussão dos conceitos de fronteira, nação e nacionalismo, aos problemas da construção do Estado-nação no interior das fronteiras herdadas da colonização, tal como aos processos de integração regional em África em contexto pós-colonial (Amaral, 1986a; 1986c; 1994; 1996a; 1997b). Na mesma linha, aprofundará ainda o estudo do complexo sector de fronteira situado no leste de Angola, no contacto do antigo reino do Barotze, posteriormente colonizado pela Grã-Bretanha como Rodésia do Norte (Zâmbia) (Amaral, 2000a). Já em 2015, oferecerá uma ampla síntese de mais de 30 páginas destas matérias, acrescida de uma nótula sobre a fixação dos limites internacionais entre as duas partes da ilha de Timor, onde uma vez mais se reconhece uma atenção sempre desperta para a bibliografia entretanto publicada sobre a questão (Amaral, 2015). 
Em paralelo, Ilídio do Amaral foi capaz de executar diversas investigações específicas sobre o reconhecimento geográfico do interior do continente africano e as expedições que sustentaram esse processo desde meados do século XVIII, ainda que dando particular atenção aos papéis desempenhados pela Comissão Central Permanente de Geografia e pela Sociedade de Geografia de Lisboa em finais do século XIX (Amaral \& Amaral, 1984b; Amaral; 1986d; 1988a; 1990). Da sua análise de documentação histórica referente aos séculos XVI e XVII resultou também uma proposta de reconstituição das características urbanas de Mbanza Kongo, capital do Reino do Congo (Amaral, 1987a; 1991a). Sensivelmente o mesmo período histórico e a mesma geografia foram tratados em O reino do Congo, os Mbundu (ou Ambundos), o reino dos Ngola (ou de Angola) e a presença portuguesa de finais do século XV a meados do século XVI (Amaral, 1996b), livro galardoado pela Academia Portuguesa de História com o «Prémio de História Calouste Gulbenkian - História da Presença Portuguesa no Mundo», em 1997. Os primórdios da presença e da administração portuguesa do «reino de Angola» e a importância das vias fluviais no apoio à penetração europeia nessas partes de África tiveram tratamento em O rio Cuanza (Angola), da barra a Cambambe: reconstituição de aspectos geográficos e acontecimentos históricos dos séculos XVI e XVII (Amaral, 2000b). Quase em simultâneo, Amaral deu à estampa O consulado de Paulo Dias de Novais. Angola no último quartel do século XVI e primeiro do século XVII (Amaral, 2000c), livro onde retomou o fio cronológico dos sucessos narrados em $O$ reino do Congo, cobrindo o consulado do primeiro governador da capitania de Angola, Paulo Dias de Novais (1575-1589). Aí retomou também vários elementos deixados anos antes num estudo comparativo das cartas de doação de diversas capitanias brasileiras e aquela outorgada a Dias de Novais para Angola, com ênfase para as medidas que afectavam a organização dos espaços (Amaral, 1991b).

Do mesmo modo que persistiu na exploração dos primórdios da construção do espaço urbano de Luanda que vinha dos seus primeiros trabalhos das décadas de 1950 e 1960 (Amaral, 2000d), Ilídio do Amaral abordou por mais de uma vez a geografia de Lisboa renascentista com base na copiosa análise de fontes da época (Amaral, 1988b; 2002b). E se os materiais de arquivo necessários para a escrita da história de África, de Angola e das respectivas cidades nunca deixaram de ser convocados para a sua obra (Amaral, 2000e; 2001; 2002c; 2007; 2014a), nos últimos anos interessou-se também pelas fontes bibliográficas relativas à exploração do Pacífico Sul protagonizada entre 1605 e 1606 pelo português ao serviço de Castela, Pedro Fernandes de Queirós (Amaral, 2014b). Esta pesquisa ocorrera-lhe ao preparar, anos antes, um artigo sobre a multiplicação de micro-Estados insulares após a II Guerra Mundial (Amaral, 1987b) e propunha-se servir de prelúdio a um inquérito mais vasto sobre os 54 Memoriales redigidos por Fernandes de Queirós em Madrid, entre 1607 e 1614, projecto que não chegou a conseguir realizar (Amaral, 2014b, p. 11-16). Em contrapartida, estes mesmos últimos anos da sua actividade científica ficaram ainda marcados por um conjunto de trabalhos centrados na história da Academia das Ciências de Lisboa (Amaral, 2009; 2012a) e em algumas raridades bibliográficas pertencentes ao espólio desta instituição (Amaral, 2012b). Desta fase final da sua inesgotável curiosidade intelectual sobressaem ainda os dois volumes consagrados aos Estudos preliminares de inéditos juvenis de José Correia da Serra (Amaral, 2012c; 2013a), correspondentes a uma abordagem aos manuscritos «Catalogue Raisonné des Voyageurs de ma Bibliothèque» (1769) e «Zibaldone di Materie Diverse» (1767-1768) desta que foi uma figura central dos tempos inaugurais da Academia das Ciências de Lisboa e do Iluminismo português, antes de se ter notabilizado na Europa e nos Estados Unidos da América como naturalista e diplomata.

Tal como se destacara com propostas inovadoras para as temáticas da Geomorfologia tropical e subtropical mercê dos seus estudos sobre os montes-ilhas (Ribeiro, 2017 [1986], p. 980), Ilídio do Amaral deixou um contributo original para o domínio da Geografia Urbana de África, o qual muito contribuiu para autonomizar o estudo dos espaços urbanos no contexto da Geografia portuguesa do século XX. Hábil gestor de instituições de ensino e investigação e divulgador científico perseverante, foi protagonista destacado da difícil transição dos estudos geográficos tropicais da última fase do império 
colonial português para o contexto da descolonização e, posteriormente, de consolidação de uma nova semântica que substituiu os "países tropicais» pelos "países do Sul» e a antiga «tropicologia» pelas novas aproximações ao «Sul Global» (Amaral, 2013b). Entre os muitos reconhecimentos e louvores que recebeu em vida, Ilídio do Amaral foi condecorado em 2007 com a medalha de Primeira Classe da Ordem do Vulcão, a maior distinção que a República de Cabo Verde atribui a personalidades civis. Poucas imagens se ajustarão melhor à figura deste investigador incansável, professor de verbo cativante e claro, homem elegante e culto, melómano inveterado que não elegia entre J. S. Bach, Beethoven e o jazz que aprendera a amar com o seu colega e amigo Francisco Tenreiro.

Ilídio do Amaral morreu preparando um trabalho sobre a geografia das Utopias dos séculos XVI e XVII, tema a que dizia ter chegado por via dos catálogos manuscritos do jovem José Correia da Serra e das suas investigações sobre as viagens e os sonhos quiméricos que animaram Pedro Fernandes de Queirós na sua busca de um continente austral. Estas Utopias, mesmo inacabadas, não deixam de ser também a comovente imagem de uma vida que foi uma longa e preenchida viagem.

\section{LISTA BIBLIOGRÁFICA}

Almada, A. (2014). A Insularidade enquanto objecto de estudo da Geografia humana: do exotismo ao reconhecimento institucional. In J. García Álvarez, J. C. Garcia (Coord.), História da Geografia e Colonialismo (pp. 111-126). Lisboa: Centro de Estudos Geográficos.

Almeida, A. C. de, et al. (Coord.). Fragmentos de um retrato inacabado. A Geografia de Coimbra e as metamorfoses de um país. Coimbra: Centro de Estudos Geográficos.

Amaral, I. do (1960). Aspectos do povoamento branco de Angola. Lisboa: Junta de Investigações do Ultramar.

Amaral, I. do (1962). Ensaio de um estudo geográfico da rede urbana de Angola. Lisboa: Junta de Investigações do Ultramar.

Amaral, I. do (1963). África. In Enciclopédia Luso-Brasileira de Cultura, vol. 1 (cols. 572-582). Lisboa: Editorial Verbo. Amaral, I. do (1963-1964). Francisco Tenreiro (1921-1963). Boletim do Centro de Estudos Geográficos, 3(20-21), 5-12. Amaral, I. do (1964). Santiago de Cabo Verde. A Terra e os Homens. Lisboa: Junta de Investigações do Ultramar.

Amaral, I. do (1966a). Síntese geomorfológica mundial. Finisterra - Revista Portuguesa de Geografia, 1(1), 111-114.

Amaral, I. do (1966b). Flutuações climáticas do Globo. Finisterra - Revista Portuguesa de Geografia, 1(1), 114-119.

Amaral, I. do (1966c). Megalopolis. Finisterra - Revista Portuguesa de Geografia, 1(1), 131-135.

Amaral, I. do (1966d). Livros novos de Geografia Física. Finisterra - Revista Portuguesa de Geografia, 1(1), 135-137.

Amaral, I. do (1966e). Johannesburg. Do campo mineiro à conurbação. Finisterra - Revista Portuguesa de Geografia, $1(2), 240-256$.

Amaral, I. do (1966f). A propósito de dois atlas climáticos. Finisterra - Revista Portuguesa de Geografia, 1(2), $273-283$.

Amaral, I. do (1966g). O CBD, um problema de geografia espacial. Finisterra - Revista Portuguesa de Geografia, 1(2), 284-287.

Amaral, I. do (1967a). Litoral da ilha de Santiago (Cabo Verde), na área da Praia. Finisterra - Revista Portuguesa de Geografia, 2(4), 292-293.

Amaral, I. do (1967b). Livros novos de Geografia Física. Finisterra - Revista Portuguesa de Geografia, 2(4), $266-269$.

Amaral, I. do (1968). Luanda. Estudo de Geografia Urbana. Lisboa: Junta de Investigações do Ultramar.

Amaral, I. do (1969a). Beira, cidade e porto do Índico. Finisterra - Revista Portuguesa de Geografia, 4(7), 76-93.

Amaral, I. do (1969b). Curriculum vitce de Ilídio Melo Peres do Amaral. Lisboa: s.n.

Amaral, I. do (1969c). Inserberge (ou montes-ilhas) e superfícies de aplanação na bacia do Cubal da Hanha, em Angola. Garcia de Orta, 17(4), 475-526.

Amaral, I. do (1970). Aspectos do relevo do Noroeste de Angola entre os rios Loge e Cuanza. In Curso de Geologia do Ultramar, vol. 2 (pp. 67-80). Lisboa: Junta de Investigações do Ultramar.

Amaral, I. do (1973a). Formas de Inselberge (ou montes-ilhas) e de meteorização superficial e profunda em rochas graníticas do Deserto de Moçâmedes (Angola), na margem direita do rio Curoca. Garcia de Orta - Série Geografia, 1(1), 1-34.

Amaral, I. do (1973b). Contribuição para o conhecimento do Karst ou carso de Nova Caipemba, no noroeste de Angola. Garcia de Orta - Série Geografia, 1(2), 1-28.

Amaral, I. do (1973c). Nota sobre o Karst ou carso do planalto da Humpata (Huíla) no sudoeste de Angola. Garcia de Orta - Série Geografia, 1(2), 29-36. 
Amaral, I. do (1973d). Imagens do deserto de Moçâmedes (Angola). Finisterra - Revista Portuguesa de Geografia, $8(16), 317-321$.

Amaral, I. do (1974a). Alguns aspectos geomorfológicos do litoral da ilha de Santiago (arquipélago de Cabo Verde. Garcia de Orta - Série Geografia, 2(1), 19-28.

Amaral, I. do (1974b). A propósito de formas escavadas em leitos fluviais e em vertentes de rochas graníticas no deserto de Moçâmedes (Angola). Garcia de Orta - Série Geografia, 2(1), 1-18.

Amaral, I. do (1977). Paisagens morfológicas do deserto de Moçâmedes (Angola) entre os rios Curoca e Cunene (1. a parte). Garcia de Orta - Série Geografia, 4(1-2), 1-28.

Amaral, I. do (1979). A «Escola geográfica de Lisboa» e a sua contribuição para o conhecimento geográfico das Regiões Tropicais. Lisboa: Centro de Estudos Geográficos, (polic.).

Amaral, I. do (1980-1981a). Bibliografia geral de Cabo Verde (Anotada e ilustrada), 2 vols. Lisboa: Centro de Estudos Geográficos, (polic.).

Amaral, I. do (1980-1981b). Entre o Cunene e o Cubango, ou a propósito de uma fronteira africana. Garcia de Orta Série Geografia, 6(1-2), 1-50.

Amaral, I. do (1981a). Notas acerca do ensino e da investigação científica em Geografia, em Portugal. In I Coloquio Ibérico de Geografía (pp. 23-33). Salamanca: Universidad de Salamanca.

Amaral, I. do (1981b). Homenagem a Orlando Ribeiro. Finisterra - Revista Portuguesa de Geografia, 16(31), 5-14.

Amaral, I. do (1981c). Bibliografia científica de Orlando Ribeiro. Lisboa: Centro de Estudos Geográficos, (polic.).

Amaral, I. do (1982a). Paisagens morfológicas do deserto de Moçâmedes (Angola), entre os rios Curoca e Cunene (2. ${ }^{a}$ parte). Garcia de Orta - Série Geografia, 7(1-2), 1-34.

Amaral, I. do (1982b). Apontamentos para a história do ensino universitário de Geografia em Portugal. In II Colóquio Ibérico de Geografia, Lisboa, 1980 - Comunicações, vol. 1 (pp. 135-138). Lisboa: Centro de Estudos Geográficos.

Amaral, I. do (1982c). Entre o Cunene e o Cubango, ou a propósito de uma fronteira africana. Lisboa: Centro de Estudos Geográficos, (polic.).

Amaral, I. do (1983a). Geógrafos e Geografia na Faculdade de Letras de Lisboa. Revista da Faculdade de Letras, Número (extra-série), comemorativo do cinquentenário da Revista da Faculdade de Letras de Lisboa, 68-82.

Amaral, I. do (1983b). Estudos de Geografia das Regiões Tropicais (Contribuições da «Escola Geográfica de Lisboa»). Garcia de Orta - Série Geografia, 8(1-2), 1-44.

Amaral, I. do (1984). Homenagem a Orlando Ribeiro. In Livro de Homenagem a Orlando Ribeiro, vol. 1. Lisboa: Centro de Estudos Geográficos, 19-26.

Amaral, I. do (1985). Processos e formas de evolução do relevo em rochas da orla sedimentar do deserto de Moçâmedes (Angola). 1. ${ }^{\text {a }}$ parte. Garcia de Orta - Série Geografia, 10(1-2), 1-40.

Amaral, I. do (1986a). The geographical factor in the formation of modern states. Finisterra - Revista Portuguesa de Geografia, 21(41), 57-76.

Amaral, I. do (1986b). Terceira (Açores). Estudo geográfico. Finisterra - Revista Portuguesa de Geografia, 21(41), 166-174.

Amaral, I. do (1986c). Fronteiras do Sahel: alguns aspectos geográficos. Garcia de Orta - Série Geografia, 11(1-2), 1-54.

Amaral, I. do (1986d). Progressos do conhecimento geográfico da África em finais do século XIX. In História e desenvolvimento da ciência em Portugal, vol. 2 (pp. 1141-1171). Lisboa: Academia das Ciências de Lisboa.

Amaral, I. do (1987a). Mbanza Kongo, cidade do Congo, ou São Salvador. Contribuição para o conhecimento geográfico de uma aglomeração urbana africana ao sul do Equador, nos séculos XVI e XVII. Garcia de Orta Série Geografia, 12(1-2), 1-40.

Amaral, I. do (1987b). A irrupção de Estados-insulares após a Segunda Guerra Mundial: um facto novo em Geografia Política. Finisterra - Revista Portuguesa de Geografia, 22(44), 297-359.

Amaral, I. do (1988a). Projectos portugueses da travessia da África central: uma viagem ao Nordeste de Angola em meados do século XVIII. In Os Portugueses e o Mundo. Conferência Internacional, vol. 2 (pp. 120-132). Porto: Fundação António José de Almeida.

Amaral, I. do (1988b). Lisboa uma capital do Renascimento. In O Humanismo português, 1500-1600 (pp. 619-652). Lisboa: Academia das Ciências de Lisboa.

Amaral, I. do (1990). Presença portuguesa em África e aculturação: reflexões a partir de três textos dos séculos XVII, XVIII e XIX. In Os Portugueses e o Mundo. Conferência Internacional, vol. 5 (pp. 39-48). Porto: Fundação António José de Almeida.

Amaral, I. do (1991a). Notas de geografia histórica sobre uma capital africana do século XVI: Mbanza Kongo, no Reino do Congo. In J. V. Serrão (Org.), Estudos de homenagem a Jorge Borges de Macedo (pp. 291-310). Lisboa: Instituto Nacional de Investigação Científica.

Amaral, I. do (1991b). Medidas portuguesas para a organização dos novos territórios nas margens continentais do Atlântico sul no século XVI: apontamentos de geografia histórica. Revista da Universidade de Coimbra, 36, 277-316. 
Amaral, I. do (1992). Contribuição dos geógrafos portugueses para o conhecimento científico das regiões tropicais. In História e desenvolvimento da ciência em Portugal no século XX, vol. 3 (pp. 1609-1628). Lisboa: Academia das Ciências de Lisboa.

Amaral, I. do (1994). New reflections on the theme of international boundaries. In Clive H. Schofield (Ed.), Global boundaries. World boundaries, vol. 1 (pp. 16-23). London; New York: Routledge.

Amaral, I. do (1995). A África no limiar do século XXI: um continente em crise. In Enciclopédia Luso-Brasileira de Cultura, vol. 23 (pp. 387-418). Lisboa: Editorial Verbo.

Amaral, I. do (1996a). Boundaries in post-colonial Africa and the building of the national territory. In W. Blocmans, J. B. de Macedo, J.-P. Genet (Eds.), The heritage of the pre-industrial European state. The origins of the modern state in Europe (pp. 197-210). Lisboa: Arquivos Nacionais/Torre do Tombo.

Amaral, I. do (1996b). O reino do Congo, os Mbundu (ou Ambundos), o reino dos Ngola (ou de Angola) e a presença portuguesa de finais do século XV a meados do século XVI. Lisboa: Instituto de Investigação Científica Tropical.

Amaral, I. do (1997a). Homenagem ao Professor Orlando Ribeiro. In A. Réffega, et al. (Eds.), A erupção vulcânica de 1995 na ilha do Fogo (Cabo Verde) (pp. 235-356). Lisboa: Instituto de Investigação Científica Tropical.

Amaral, I. do (1997b). Fronteiras internacionais africanas. In J. R. Magalhães, J. C. Garcia (Orgs.), As Fronteiras de África (pp. 13-22). Lisboa: Comissão Nacional para as Comemorações dos Descobrimentos Portugueses.

Amaral, I. do (2000a). Partilhas territoriais tradicionais e coloniais na África ao sul do Sara: jogos políticos africanos no rescaldo da Guerra de 1914-1918. In M. E. M. Santos (Ed.), Actas da III Reunião Internacional de História de África (pp. 47-70). Lisboa: Instituto de Investigação Científica Tropical.

Amaral, I. do (2000b). O rio Cuanza (Angola), da barra a Cambambe: reconstituição de aspectos geográficos e acontecimentos históricos dos séculos XVI e XVII. Lisboa: Instituto de Investigação Científica Tropical.

Amaral, I. do (2000c). O consulado de Paulo Dias de Novais. Angola no último quartel do século XVI e primeiro do século XVII. Lisboa: Instituto de Investigação Científica Tropical.

Amaral, I. do (2000d). Primórdios da construção do espaço urbano em Luanda nos finais do século XVI e princípios do século XVII: o regime de doação de 'chãos"'. In Construindo o passado angolano: as fontes e a sua interpretação. Actas. II Seminário Internacional sobre a História de Angola (pp. 545-564). Lisboa: Comissão Nacional para as Comemorações dos Descobrimentos Portugueses.

Amaral, I. do (2000e). Duarte Lopes, natural de Benavente, e as suas relações com o Reino do Congo e as Índias Ocidentais no último quartel do século XVI: o viajante, mercador e embaixador. In D. Lopes, F. Pigafetta, Relação do Reino do Congo e das Terras Circunvizinhas (pp. 5-39). Benavente: Câmara Municipal de Benavente.

Amaral, I. do (2001). Análise das estruturas e funções urbanas na África Ocidental antes da presença europeia. In W. Rossa, R. Araujo, H. Carita (Eds.), Universo Urbanístico Português 1415-1822: Actas do Colóquio Internacional (pp. 1833-1846). Lisboa: Comissão Nacional para as Comemorações dos Descobrimentos Portugueses.

Amaral, I. do (2002a). Luanda e os seus dois arcos complexos de vulnerabilidade e risco. Territorium. Revista de Geografia Física Aplicada no Ordenamento do Território e Gestão de Riscos Naturais, 9, 89-115.

Amaral, I. do (2002b). Lisboa: cidade de Quinhentos. In D. de Góis; A. A. Nascimento (Ed.), Elogio da Cidade de Lisboa = Urbis Olisiponis Descriptio (pp. 11-40). Lisboa: Guimarães Editores.

Amaral, I. do (2002c). Construindo a História de Angola: a importância da utilização cruzada de fontes. (Reflexões de um geógrafo). Lisboa: Instituto de Investigação Científica Tropical.

Amaral, I. do (2006). O rio Cambongo-Negunza e os seus afluentes: um exemplo da complexidade de padrões de drenagem em Angola. Finisterra - Revista Portuguesa de Geografia, 41(82), 15-48.

Amaral, I. do (2007). Sobre as relações entre a Geografia e a História. Reflexões de um geógrafo. Luanda: III Encontro Internacional sobre História de Angola.

Amaral, I. do (2009). Nótulas históricas sobre os primeiros tempos da Academia das Ciências de Lisboa. Lisboa: ed. do Autor, (polic.).

Amaral, I. do (2010). Recordando o Grande Amigo e Colega Francisco Tenreiro... In I. Mata (Org.), Francisco José Tenreiro: as múltiplas faces de um intelectual (pp. 35-40). Lisboa: Edições Colibri.

Amaral, I. do (2012a). Nótulas históricas sobre os primeiros tempos da Academia das Ciências de Lisboa. Lisboa: Edições Colibri.

Amaral, I. do (2012b). As Bíblias e outras raridades das colecções de Frei Manuel do Cenáculo: da sua existência na Biblioteca da Academia das Ciências de Lisboa. Lisboa: Edições Colibri.

Amaral, I. do (2012c). Estudos preliminares de inéditos juvenis de José Correia da Serra. A propósito do "Catalogue Raisonné des Voyageurs de ma Bibliothèque" (1769). Lisboa: Edições Colibri.

Amaral, I. do (2013a). Estudos preliminares de inéditos juvenis de José Correia da Serra. A propósito dos "Zibaldone di Materie Diverse I a IV”. Lisboa: Edições Colibri. 
Amaral, I. do (2013b). Cidades na África Subsariana no século XXI, como partes do Sul Global. Praia: Universidade de Cabo Verde.

Amaral, I. do (2014a). Subsídios para a História da Geografia no primeiro decénio do século XXI. In J. García Álvarez, J. C. Garcia (Coord.), História da Geografia e Colonialismo (pp. 21-41). Lisboa: Centro de Estudos Geográficos.

Amaral, I. do (2014b). Pedro Fernandes de Queirós ou Pedro Fernández de Quirós (1565-1615), o descobridor de ilhas, o visionário de um continente cheio de riquezas "en la parte Austral Incognita" e de projectos para a sua colonização: quando a história, a geografia e a Utopia se cruzam (séculos XVI-XVII). Lisboa: Edições Colibri.

Amaral, I. do (2015). O papel da Sociedade de Geografia de Lisboa na delimitação das fronteiras das antigas colónias portuguesas em África e de Timor. Boletim da Sociedade de Geografia de Lisboa, 133(1-2), 33-60.

Amaral, A., \& Amaral, I. (1984a). Bibliografia científica de Orlando Ribeiro. Lisboa: Centro de Estudos Geográficos.

Amaral, A., \& Amaral, I. (1984b). A viagem dos pombeiros angolanos Pedro João e Amaro José entre Mucari (Angola) e Tete (Moçambique), em princípios do século XIX, ou a história da primeira travessia da África central. Garcia de Orta - Série Geografia, 9(1-2), 17-58.

Amaral, I. do, \& Amaral, A. (1996). Bibliografia científica de Ilídio do Amaral. Lisboa: Centro de Estudos Geográficos.

Amaral, I. do, \& Amaral, A. (2016). Bibliografia científica de Ilídio do Amaral. Lisboa: Centro de Estudos Geográficos.

Amaral, I. do, \& Daveau, S. (Org.), (1982). Bibliografia Geográfica de Portugal, vol. 2, 1947-1974. Lisboa: Centro de Estudos Geográficos.

Castelo, C. (2012). Investigação científica e política colonial portuguesa: evolução e articulações, 1936-1974. História, Ciência, Saúde - Manguinhos, 19(2), 391-408. Disponível em: https://dx.doi.org/10.1590/S0104-59702012000 200003

Castelo, C. (2013). Ciência, Estado e desenvolvimento no colonialismo português tardio. In M. B. Jerónimo (Org.), O Império Colonial em questão (sécs. XIX-XX). Poderes, saberes e instituiçães (pp. 349-387). Lisboa: Edições 70.

Correia, E., Amaral, I. do, \& Gonçalves, A. (1995). Bibliografia Geográfica de Cabo Verde, vol. 1. Lisboa: Instituto de Investigação Científica Tropical.

Cruz, B. P. da (2016). O Gabinete dos Negócios Políticos do Ministério do Ultramar. In D. R. Curto (Dir.), Políticas coloniais em tempo de revoltas - Angola circa 1961 (pp. 59-125). Porto: Edições Afrontamento.

Ferreira, A. de B., Gaspar, J, \& Medeiros, C. A. (1986). Notas em torno do desenvolvimento da Geografia em Portugal. Anales de Geografía de la Universidad Complutense, 6, 63-79.

Ferreira, P. R. (2013). Os reitores. In S. C. Matos, J. Ramos do Ó (Coord.), A Universidade de Lisboa nos séculos XIX e XX, vol. 1 (pp. 327-385). Lisboa: Tinta-da-China.

Gourou, P. (1958). São Miguel des Açores. Annales de Géographie, 67(362), 367-370.

Gourou, P. (1968). Santiago de Cabo Verde. La terre et les hommes, de Ilídio de [sic] Amaral. Annales de Géographie, 77(419), 106-110.

Instituto de Investigação Científica Tropical [IICT] (1983). Da Commissão de Cartographia (1883) ao Instituto de Investigação Científica Tropical (1983): 100 Anos de História. Lisboa: Instituto de Investigação Científica Tropical.

Lautensach, H., \& Feio, M. (Org.) (1948). Bibliografia Geográfica de Portugal. Lisboa: Centro de Estudos Geográficos.

Medeiros, C. A. (1999). Homenagem a Ilídio do Amaral. Finisterra - Revista Portuguesa de Geografia, 34(67-68), 5-9.

Ministério do Ultramar [MU] (1968). Junta de Investigações do Ultramar: seus organismos; pessoal científico, técnico e auxiliar. $8^{\mathrm{a}}$ edição. Lisboa: Centro de Documentação Científica Ultramarina, (mimeogr.).

Oliveira. F. R. de (2016). Orlando Ribeiro - Cadernos de campo, Moçambique 1960-1963. Luso-Brazilian Review, 53(2), E45-E48. Disponível em: http://lbr.uwpress.org/content/53/2/E45.full.pdf+html

Rebelo, F. (1992). A Geografia Física em Portugal no séc. XX. In História e desenvolvimento da ciência em Portugal no século XX, vol. 3 (pp. 1153-1585). Lisboa: Academia das Ciências de Lisboa.

Rebelo, F. (1999). Riscos de inundação rápida em Cabo Verde. Apontamentos de observação numa breve visita à Praia e ao Mindelo em Junho de 1999. Finisterra - Revista Portuguesa de Geografia, 34(67-68), 47-55.

Ribeiro, O. (1954). A ilha do Fogo e as suas erupções Lisboa: Junta de Investigações do Ultramar.

Ribeiro, O. (1968). Primeiro Seminário Internacional de Geografia. Finisterra - Revista Portuguesa de Geografia, 3(6), $135-146$.

Ribeiro, O. (2017). Mestres, Colegas, Discípulos, org. Suzanne Daveau, vol. 2. Lisboa: Fundação Calouste Gulbenkian.

Ribeiro, O., Feio, M, \& Amaral, I. (1961). Nota preliminar acerca do relevo de Angola entre os rios Zaire e Loge. Garcia de Orta, 9(3), 509-514.

Sociedade Portuguesa de Espeleologia [SPE] (2017). Morreu o Prof. Ilídio do Amaral, antigo presidente da SPE. Disponível em: http://spe.pt/espeleologia/noticias-espeleologia/389-morreu-o-prof-ilidio-do-amaral-antigo-presidente-da-spe 